\title{
Yacyretá y los efectos de segunda generación. Desarrollo urbano, asentamientos y avance de la ciudad formal
}

\author{
Yacyretá and the second-generation effects. Urban development, \\ settlements and advancement of the formal city
}

\author{
Walter Fernando Brites ${ }^{1}$ \\ Fecha de recepción: 30-01-2020 - Fecha de aceptación: 16-06-2020 \\ Hábitat y Sociedad (ISSN 2173-125X), n. ${ }^{\circ}$ 13, noviembre de 2020, pp. 229-248. \\ http://dx.doi.org/10.12795/HabitatySociedad.2020.i13.13
}

\section{Summary}

The socio-spatial and urban effects of the Yacyretá project, today constitute a complex and still unfinished phenomenon, and can be fully interpreted in the long time of its execution. Thus, from a descriptive, processes and historical methodology, it has been analysed the way in which the hydroelectric project, located close to the city of Posadas (Argentina), generated strong and intermittent processes of urban development, resulting from the effect of great infrastructure works and remodelling of the city. The study shows how the increase of the waterfront, the removal of settlements, as well as the relocation, the regeneration and revaluation of new urban areas, etc., have situated a large part of the informal city at the crossroads. Among the findings, it's stands out that the effects of the hydroelectric project continue, despite having finalized, , exposing an old informal settlements spaces, often adjacent to the new coastline, where the revaluation and redevelopment is increasing. This is a gradual and simultaneous process with changes in urban legislation, and new urban plans that are consolidating the development of the formal city, re-qualified and open to the market.

\section{Key words}

Development; Urban Changes; Habitat; Settlements; City

\section{Resumen}

Los efectos socio-espaciales y urbanos del proyecto Yacyretá, constituyen a día de hoy, un fenómeno complejo y aún inacabado, pudiendo ser interpretado exhaustivamente a través de su prolongado tiempo de ejecución. Así, desde una metodología descriptiva, procesual e histórica se analiza la manera en que el proyecto hidroeléctrico, al situarse próximo a la ciudad de Posadas (Argentina), generó fuertes e intermitentes procesos de desarrollo urbano, de la mano de la impronta de grandes obras de infraestructura y remodelación urbanística/paisajística de la ciudad. El estudio demuestra cómo el aumento del frente fluvial, la remoción de asentamientos y la relocalización, la regeneración y la revalorización de nuevas áreas urbanas, etc., han situado en la encrucijada a gran parte de la ciudad informal. Entre los hallazgos, se señala que, a pesar de haber concluido el proyecto hidroeléctrico, sus efectos continúan, poniendo al descubierto viejos asentamientos informales espacios muchas veces adyacentes a la nueva línea de costa, donde la revalorización/reurbanización es creciente. Se trata de un proceso paulatino y simultáneo con cambios en la legislación urbana, nuevos planes de ordenamiento y planificación, que están consolidando el avance de la ciudad formal, recualificada y abierta al mercado.

\section{Pallabras clave}

Desarrollo; Cambios Urbanísticos; Hábitat; Asentamientos; Ciudad

1 Dr. en Antropología Social (2012) y Master en Políticas Sociales (2006). Investigador Adjunto en el Consejo Nacional de Investigaciones Científicas y Técnicas (CONICET) y en el Instituto de Estudios Sociales y Humanos IESyH. UNaM Argentina. Profesor en el área de metodología de la investigación en la Universidad de la Cuenca del Plata. Investigador Asociado al grupo de trabajo "Desigualdades Urbanas" del Consejo Latinoamericano de Ciencias Sociales (CLACSO). Fue miembro de la Comisión de Antropología Urbana de la Unión Internacional de Ciencias Antropológicas (IUAES) y de los grupos de trabajo Hábitat Popular e Inclusión Social y Derecho la Ciudad en Latinoamérica CLACSO 2010-2018. E-mail: briteswalter@yahoo.com.ar. ORCID: 0000-0003-2801-5792. 


\section{Introducción}

Con foco en la ciudad de Posadas (Argentina), este artículo trata de redimensionar las heterogéneas y multidimensionales consecuencias socio-urbanas que generó en el tiempo el mega Proyecto Hidroeléctrico Yacyretá, gestionado a través de la Entidad Binacional Yacyretá (EBY) Argentina-Paraguay, que durante el largo e intermitente lapso de su ejecución (más de 30 años), debió de mitigar los efectos del anegamiento, recomponiendo la trama urbana, construyendo nuevas infraestructuras y espacios públicos, rehabilitando amplios sectores urbanos y relocalizando a miles de familias en nuevos conjuntos habitacionales. En otras palabras, el Proyecto Yacyretá fue clave para el desarrollo urbano de Posadas, ${ }^{2}$ con efectos que en la actualidad continúan generando nuevas materialidades urbanas y consecuencias socioespaciales.

En este sentido, en base al análisis diacrónico del efecto Yacyretá, analizamos aquí cómo las acciones de transformación urbana del proyecto hidroeléctrico fueron solamente efectos de primer tiempo sobre el espacio urbano. Por otro lado, sostenemos que, en la actualidad, al efecto Yacyretá se han amalgamado otros procesos: cambios en la legislación urbana, revalorización del suelo, especulación inmobiliaria, y nuevas formas de desplazamientos, procesos que pueden ser considerado efectos de segunda generación, que, entre variadas consecuencias, están presionando a los sectores populares y las urbanizaciones informales que subsistieron en intersticios de la revalorización urbana. Concretamente, los procesos de revalorización están aprovechando las obras que ha dejado Yacyretá, de modo que los asentamientos y barrios populares que no fueron removidos, hoy están siendo objeto de la especulación inmobiliaria y potenciales procesos de desplazamientos de acuerdo a su proximidad al nuevo frente fluvial y su recurso paisajístico.

Es evidente que muchos barrios/asentamientos han comenzado paulatinamente a ser cercados, acorralados por obras públicas, así como por nuevas y crecientes edificaciones privadas que están transformando el entorno (Brites, 2017). La remodelación urbanística trajo consigo la ciudad formal mientras que los lugares que ocupan estos asentamientos son llamados informales, generalmente precarios, pero estratégicos en el nuevo contexto urbano. Las estructuras de oportunidades y las ventajas asociadas al entorno (proximidad al mercado de trabajo, a nuevos espacios de esparcimiento, al centro urbano, etc.) se convierten en una situación que amenaza la permanencia del hábitat de estos pobladores.

\section{Diseño metodológico y aproximaciones teóricas}

Este estudio responde a una metodología de orden descriptiva, de análisis procesual y longitudinal (temporal), que recuperó parte de variadas fases y experiencias de investigación sobre este fenómeno en Posadas. La naturaleza del problema ha implicado el desarrollo de un trabajo de campo multi-situado en distintos espacios y contextos de la ciudad. Por otro lado, esta investigación se ha nutrido de un trabajo de archivo, proveniente tanto de fuentes gubernamentales como no gubernamentales, entre los que se han incluido: documentos e informes, diagnósticos, base de datos, etcétera.

En cuanto a la discusión teórica, esta propuesta realiza una "triangulación de aproximaciones teóricas" que analizan los efectos de los gran-

2 Esta represa afectó por igual a la ciudad paraguaya de Encarnación, ubicada en la costa del río Paraná frente a Posadas. 
des proyectos de desarrollo, no solo sobre las condiciones de vida de los sectores desplazados, sino en el espacio territorial y en la emergencia de otros fenómenos urbanos que se proyectan en prospectiva. La experiencia de Yacyretá, es analizada a la luz de los efectos de los Proyectos de Gran Escala (Lins Ribeiro, 1985) en cuanto a sus dimensiones y el carácter temporario, pero también en base a la noción "grandes proyectos urbanos" con complejidad económica y social (Lungo, 2011). En otras palabras, el enfoque aquí propuesto entiende a los efectos socio-espaciales del proyecto como procesos que guardan continuidad en el espacio y en el tiempo (Catullo, 2006), de modo que las consecuencias de los grandes proyectos instalan acelerados procesos de cambios socioculturales, cuyos efectos superan la temporalidad que la construcción de la obra requirió (Radovich 2017).

Por otro lado, al margen del denominado "drama social" y del "efecto entrópico" de las relocalizaciones compulsivas en las estrategias adaptativas (Bartolomé, 2006), se retoma aquí la idea del efecto segregador de la relocalización (Brites, 2015) que se refiere al impacto sinérgico del desplazamiento y la expoliación urbana en la agudización de las desventajas estructurales que se generan al reasentar a hogares territorios de relegación, en contextos de socialización e interacción más homogéneos.

De acuerdo a Serje (2011) el reasentamiento constituye un proceso de desposesión y pérdida, en el que las personas se ven desarraigadas de su tierra, sus redes familiares y comunitarias. El caso de Posadas, en el que la relocalización ha recaído sobre la población más pobre y sus lugares de vida, amerita la conexión del análisis con las condiciones de los denominados asentamientos informales (precarios, auto-producidos, con irregularidad dominial etc.), que, si bien son el resultado de estrategias de organización colectiva (Varela y Cravino, 2008), también han sido reconocidos como formas de crecimiento urbano (García 2005).

Las costas bajas y anegadizas (bordes el río y arroyos urbanos) en tanto hábitat de los pobres, puso en una relación ineludible a los asentamientos con el ente relocalizador, que erradicó muchas barriadas, mientras otras permanecieron en intersticios urbanos revalorizados, hoy también amenazados por el desplazamiento. En este contexto, más allá de los efectos relocalizatorios, el encuadre de la problemática del desplazamiento se desarrolla en el marco constituido por los procesos de "renovación urbana" y de erradicación de asentamientos informales, por lo que la cuestión de la "revalorización urbana" vinculada a la segregación cobra vital importancia.

En este sentido, se analizan otras cuestiones teóricas que convergen en el caso de Yacyretá, como la renovación urbana (Ugalde Monzalvo, 2012), la segregación socio-espacial, como la concentración de sectores sociales en un determinado territorio (Sabatini, Cáceres y Cerdá, 2001), con separación de ciertos grupos sociales que se mantienen con escasa o nula interacción con el resto de la sociedad u otros sectores sociales (Roitman, 2004). También el desarrollo de plusvalías urbanas y de rentas por monopolio de segregación (Jaramillo, 2003), y la gentrificación como un proceso de transformación de un espacio urbano, con sustitución social y movilidad residencial (Gasic Klett, 2013; Brites, 2017).

De modo general las categorías teóricas, se orientan al análisis de las dimensiones socio-territoriales de la ciudad, sus nuevas formas de crecimiento y valorización, teniendo en cuenta el desarrollo de nuevas 
materialidades urbanas, la creciente formación de rentas, las dinámicas del mercado inmobiliario, la producción de desigualdades sociourbanas y sus efectos específicos.

\section{Los asentamientos informales y el Proyecto Yacyretá}

Puede decirse que los asentamientos han sido parte de la consolidación urbana de Posadas, localizados desde sus inicios en los bordes del río Paraná y otros caudalosos arroyos urbanos. La existencia de asentamientos precarios en la costa de Posadas se remonta a diversos periodos, siendo el más notorio de ellos los procesos migratorios ruralurbanos desatados entre las décadas de 1960 y 1980, cuando la ciudad incrementó significativamente el tamaño de su población. La disponibilidad de tierras no urbanizadas en la franja de la costa ribereña, próxima a la ciudad, constituyó un espacio estratégico para los asentamientos, al presentar ventajas para sus residentes y fue tolerado por ser funcional a un esquema laboral de prestación de servicios a las clases medias y altas (Brites, 2012). De hecho, la configuración del borde ribereño como área de trabajo generó los primeros asentamientos irregulares, con características diferentes a la ciudad legal (Borio, 2002). En este contexto, la legislación urbana muy local, posibilitaba que diversos sectores sociales se integraran en la ocupación del espacio urbano. Una situación que dio una vuelta de página a partir del advenimiento del proyecto Yacyretá.

Las acciones de la hidroeléctrica Yacyretá en Posadas se enmarcaron en la ejecución de las obras complementarias, que fueron parte del plan de construcción de la represa a cargo de la Entidad Binacional Yacyretá (EBY) entre Argentina y Paraguay. El advenimiento del proyecto hidroeléctrico Yacyretá, y la elaboración del primer censo de familias afectadas en 1979, puso en relación ineludible a los habitantes de los asentamientos afectados con el ente relocalizador: la EBY, encargada desde el primer momento de gestionar el desplazamiento y la remoción. Un contexto en el que el crecimiento y densificación de los asentamientos iba en aumento en el área de influencia del proyecto.

La proximidad del emplazamiento de la represa generó dramáticas consecuencias para la ciudad, entre ellas la formación en la región un gran lago de 165000 hectáreas, que implicó la inundación del 10\% del distrito de Posadas; ${ }^{3}$ conjuntamente con el proceso forzoso de relocalización de más de 35000 personas. La magnitud del proyecto implicó la construcción de un conjunto de obras principales y de obras complementarias. Las primeras se refirieron exclusivamente a la producción de energía hidroeléctrica y se localizaron en la misma zona de la represa. Las segundas, en tanto construcciones complementarias, implicaron acciones orientadas a mitigar los efectos no deseados de la represa, como los descritos anteriormente.

Como marco general, las acciones del proyecto Yacyretá posibilitaron el implacable avance de la ciudad formal y la legislación urbana sobre los asentamientos y las urbanizaciones denominadas informales. Al margen de las obras de reposición de infraestructura, Yacyretá reestructuró la morfología urbana de Posadas, generando cambios en el territorio y en los patrones de ocupación del espacio urbano. Una situación que dio lugar a una serie de "relocalizaciones" compulsivas y de programas de "renovación urbana" centrados tanto en la remodelación urbanística como en la erradicación de asentamientos informales. 
Estos cambios apelaron a una visión higienística de la ciudad, acompañada de discursos eufemísticos, sobre la intrusión e ilegalidad de los asentamientos y la mejora habitacional vinculada a las ventajas del reasentamiento.

\section{Primera etapa: la relocalización}

En la ciudad de Posadas, a lo largo del margen del río Paraná y sus arroyos urbanos existían asentamientos costeros, muchos de ellos conformando barriadas caracterizadas por la pobreza de sus residentes. $\mathrm{Si}$ bien el poblamiento de esta zona data de mucho tiempo atrás, su consolidación como barriadas tuvo su punto más álgido hacia la década de 1960, impulsado por los procesos migratorios de población rural proveniente tanto del interior provincial como del Paraguay. Los asentamientos más tradicionales de ese entonces eran: El Chaquito, Villa Blosset, Villa Molas, San Cayetano, San Roque, Anfiteatro, Baradero, ${ }^{4}$ entre otros.

Conjuntamente con el poblamiento de la ribera, viviendas muy precarias comenzaron a levantarse en otros intersticios de áreas urbanas socialmente heterogéneas, dispares, pero conectadas entre sí, como la zona de El Brete, Tiro Federal, Rowing, etc. En este periodo, los asentamientos carenciados se multiplicaron y extendieron en función de la posibilidad de encontrar tierras libres, ocupando terrenos públicos y/o privados. La mayor parte de estos barrios se caracterizaban por la ilegalidad e informalidad en la ocupación del suelo. La peculiaridad de estas tierras, hasta tiempos antes del inicio de las obras de Yacyretá, era su escaso valor de mercado; entre otras circunstancias por ser tierras fiscales, deterioradas e inhabitables para las clases medias. ${ }^{5}$

El anclaje espacio-temporal del hábitat de estos sectores consolidó una trama de relaciones y prácticas con diversas funcionalidades, entre ellas la supervivencia. Por ello, las características específicas del propio contexto urbano en el que residía aquella población oficiaban como una estructura de oportunidades, en el sentido de que facilitaban una inserción laboral (aunque precaria) en las cercanías de la zona. La albañilería, la provisión de servicios doméstico a los sectores de clase media y alta, residentes en el casco urbano eran parte de las estrategias de subsistencia. ${ }^{6}$

El funcionamiento de la represa Yacyretá, a cota 83 metros sobre el nivel del mar (m s.n.m.) implicaría el anegamiento de amplias zonas urbanas, así como la realización de las obras complementarias y la previa remoción de estos barrios asentados bajo cota de afectación. De manera que, para mitigar los efectos no deseados del embalse, la EBY tuvo que realizar un paquete de acciones: expropiación de inmuebles, tratamiento costero, saneamientos de arroyos, extensión de servicios, obras viales y construcción de nuevos barrios. Esta situación, como veremos, requirió el traslado de miles de familias hacia otros puntos de la ciudad.

La primera experiencia relocalizatoria de la EBY en Posadas se remonta a los años 1983-1984, cuando fue relocalizada una importante cantidad de hogares hacia el complejo habitacional A-1, más tarde denominado por sus habitantes como "Barrio Yacyretá". El sector de procedencia de estas primeras familias relocalizadas era un populoso asentamiento conocido como "El Chaquito". Una zona ribereña marginal, pero estratégica, por su proximidad al centro urbano de Posadas. Pos-
4 En los inicios de la ciudad, varios de estos barrios tuvieron actividad portuaria en la ribera, como el viejo varadero donde varaban los barcos y con el tiempo los lugareños lo bautizaron como Baradero. 5 Como marco más general, la ausencia de una planificación urbana posibilitó que sectores altos, medios y bajos accedieran al espacio urbano; proceso que fue incidiendo en la configuración de heterogéneas áreas urbanas, un bricolaje de sectores sociales integrados en la ocupación del espacio urbano (Brites 2015). 6 Así como la realización de una gran variedad de actividades informales enmarcadas en la modalidad de "changas" (trabajos temporarios remunerados a destajo). 
teriormente, durante los años 1988-1989, la continuidad del proceso relocalizatorio implicó la ampliación del complejo A-1 hacia las chacras 92, 103 y 111 (Yohasá), con el reasentamiento de familias provenientes de diferentes áreas ribereñas, entre ellas, la ex-colonia laosiana situada en las cercanías del viejo barrio Tiro Federal. Como puede observarse en la tabla 1, no hubo una linealidad (continuidad) en el proceso de desplazamiento, debido al retraso de las obras complementarias, generando una situación que dilató el proceso de traslado entre los años 1983-2010. Toda el área costera fue declarada como "zona de no innovar", lo cual generó un escenario especialmente delicado, al agravar la situación de la población aún por relocalizar; despertando temores, incertidumbres y conflictos en relación a la planificación de la vida y el futuro de la relocalización. ${ }^{7}$

\begin{tabular}{|c|c|c|c|}
\hline Asentamientos y barrios removidos & $\begin{array}{l}\text { Conjunto } \\
\text { habitacional }\end{array}$ & $\begin{array}{l}\text { Año de } \\
\text { poblamiento }\end{array}$ & $\begin{array}{l}\text { Hogares } \\
\text { relocalizados }\end{array}$ \\
\hline $\begin{array}{l}\text { Asentamientos de Costanera Et. I II y III, Tiro Federal, El Brete, B. } \\
\text { YPF, Pira Pitá, B }{ }^{\circ} \text { San Cayetano, Ch. } 209\end{array}$ & A-1 (Yacyretá) & 1983-1984 & 1047 \\
\hline Ribera del Paraná Sec. 1, 2 y 3. & A-1C (Yohasá) & $\begin{array}{c}1988-1989 \\
\text { y } 1998-2003\end{array}$ & 798 \\
\hline $\begin{array}{l}\text { Villa Bosset, Estación de Trenes, El Chaquito, La Cantera, Villa Coz, } \\
\text { Rowing Viejo, Parque Adam, B. }{ }^{\circ} \text { José Obrero, LASA, Santa Rosa, } 2 \\
\text { de abril, Sesquicentenario, Nuevo Asentamiento, Loma Poí, Villa } \\
\text { Poujade, San Lorenzo, Santa Rita, El Laurel. A Mártires }\end{array}$ & $\begin{array}{l}\text { A-3.2 (Villa } \\
\text { Lanus) }\end{array}$ & 1990-1992 & 974 \\
\hline $\begin{array}{l}\text { Ribera del Paraná: La Cantera, Rowing Viejo, Tito Federal, El Brete, } \\
\text { B. }{ }^{\circ} \text { YPF, Pira Pitá, Villa Poujade. }\end{array}$ & $\begin{array}{l}\text { A-3.1 (Virgen } \\
\text { de Fátima) }\end{array}$ & $2002-2004$ & 1374 \\
\hline $\begin{array}{l}\text { Costanera Etapas I y II. V. Blosset, El Chaquito, B. ․ San Cayetano, } \\
\text { Rowing, San Gabriel, Nuevo Asentamiento, Est. Trenes, A Mártires, } \\
\text { Santa Rita, El Laurel, Loma Poí, }\end{array}$ & $\begin{array}{l}\text { A-4 (Nueva } \\
\text { Esperanza) }\end{array}$ & $1998-2003$ & 1664 \\
\hline Tiro Federal, Villa Congost, Villa Poujade, Pira Pitá. & $\begin{array}{l}\text { San Isidro } 1 .^{\mathrm{a}} \\
\text { etapa }\end{array}$ & $2008-2010$ & 1431 \\
\hline \multirow[t]{2}{*}{ Franja de transporte Norte y Sur } & $\begin{array}{l}\text { San Isidro } 2 .^{\text {a }} \\
\text { etapa }\end{array}$ & & 153 \\
\hline & Total & & 7393 \\
\hline
\end{tabular}

Tabla 1. El proceso de relocalización y los asentamientos removidos. Fuente: elaboración propia en base a EBY, 2009 y 2011
7 Un ejemplo de ello fue ubicación estratégica del barrio el Brete dentro de la ciudad, en términos de su centralidad y de la cercanía del río, que lo ha convertido en un objeto de disputa a fin de desalojar/relocalizar a familias asentadas más allá de la cota de afectación.
Durante la década de 1990, la EBY construyó paulatinamente una serie de conjuntos habitacionales para compensar el desplazamiento de los hogares precarios, cuyo número fue creciente, debido a las demoras del proyecto hidroeléctrico. Cabe señalar aquí que todas las experiencias de relocalizaciones han generado rupturas de redes de relaciones (familiares, vecinales, clientelares, etc.), así como desarticulaciones sociales, que repercutieron en las estrategias reproductivas y de supervivencias de las familias implicadas.

Durante los años noventa, gran parte de los asentamientos carenciados de Posadas estuvieron monitoreados por la EBY a través de los relevamientos de Verificación de Áreas Urbanas (VAU), así como por la Universidad Nacional de Misiones, a partir de los relevamientos de los Bolsones de Pobreza (Proyecto Pobur, 1994-1995). A los fines de localizar e identificar un bolsón de pobreza, la descripción operativa trató de detectar un conjunto de al menos 10 viviendas precarias, con necesidades básicas insatisfechas, localizadas en el perímetro de una manzana. En aquel entonces, el relevamiento detectó 81 bolsones de pobreza en 
la ciudad de Posadas, de los cuales 7 se localizaban en zonas centrales, mientras que el $33 \%$ de los registrados, se asentaban en la zona costera, por debajo de la cota de inundación del embalse o en zonas de inundaciones periódicas (Pobur, 1996).

El Relevamiento de Asentamientos Urbanos (RAU) de los años 8990 detectó 4259 hogares del lado argentino y sentó las bases para el proceso relocalizatorio que años más tarde, en 1992, posibilitó el poblamiento del conjunto habitacional A-3.2, situado en la zona de Villa Lanús de Posadas. Fue un proceso relocalizatorio largo e intermitente que se extendió hasta los años 1997 y 1998, donde fueron reasentados hogares provenientes de diferentes asentamientos carenciados cercanos tanto a la ribera del Paraná como a la vera de arroyos urbanos. La cota de afectación llegó a alcanzar a estas áreas. Algunos sectores de asentamientos como Villa Poujade, y las Chacras 26, 25, 216, 219 y 222, entre otras, fueron trasladados a este complejo habitacional. Aunque la última etapa de poblamiento del conjunto A-3.2 fue completada con población desplazada del área en el que se inició el primer tramo de la avenida Costanera.

La elevación gradual de los niveles del río Paraná implicó un énfasis en el tratamiento costero, desarrollándose el ambicioso "Proyecto Costanera" que significó el mayor programa de renovación urbana en la ciudad de Posadas. En 1997, el proyecto Costanera fue un acuerdo firmado entre la Municipalidad de Posadas y el Gobierno Provincial, en paralelo a los esperados aumentos de la cota del emprendimiento Yacyretá. ${ }^{8}$ Propuesto como una "obra del siglo", el proyecto planteó a nivel ideológico/discursivo una modificación del paisaje urbano, con fines recreativos, urbanísticos, etc., lo que ayudó a fomentar distintas

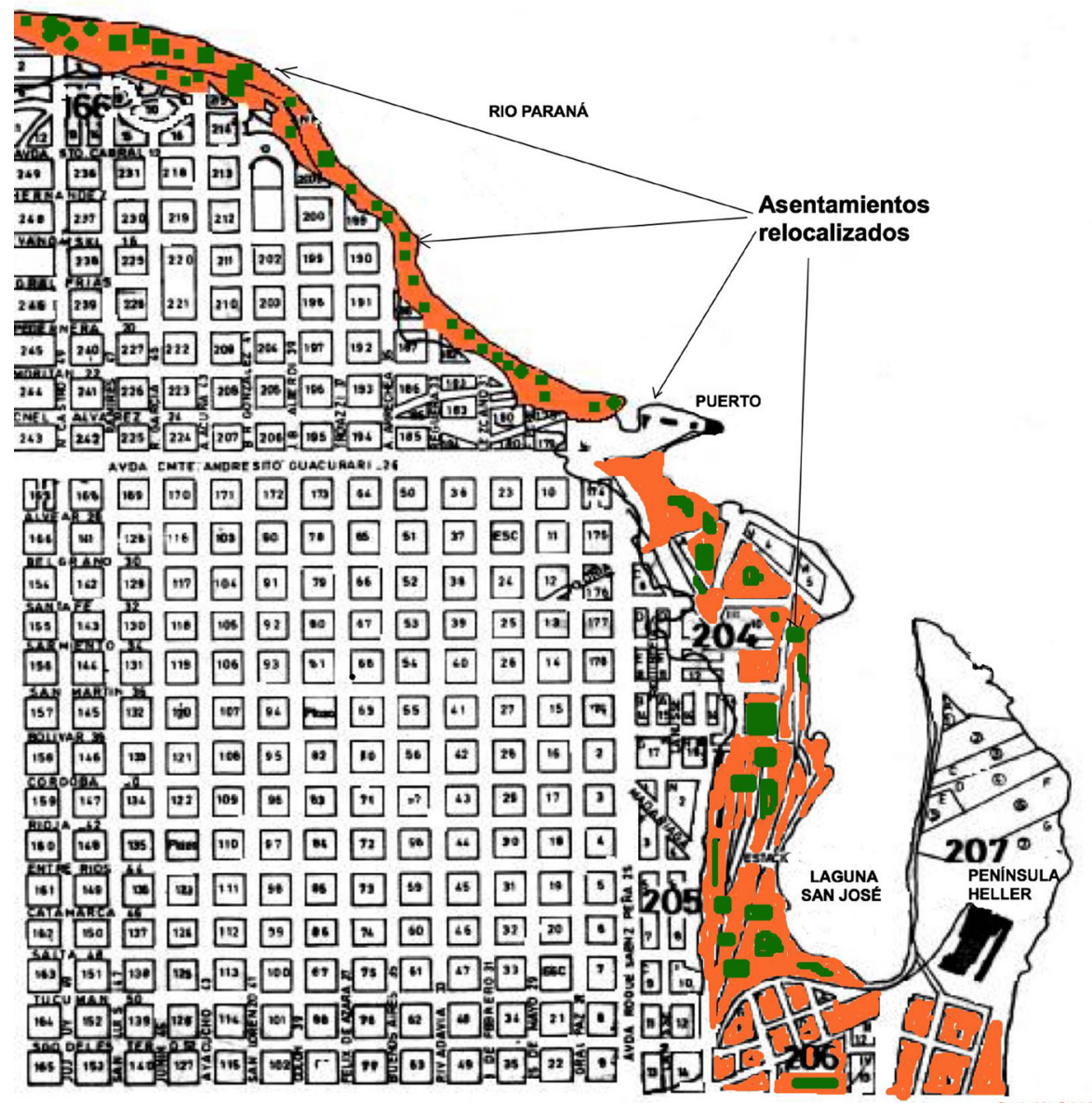

Figura 1. Mapa del área costera pericentral desplazada y renovada. Fuente: elaboración propia, en base a Dirección de Catastro, 1988.

8 En realidad, el proyecto no fue el resultado de una decisión coyuntural, ya que los antecedentes se remontan al Plan Posadas del año 1972, cuando en ese entonces se planteó el advenimiento de las obras complementarias de la represa de Yacyretá. 
visiones positivas, así como el posicionamiento de la opinión pública a favor de los programas de renovación. La obra fue publicitada como "el balcón al Paraná" y se la utilizó para la promoción turística de la ciudad, ya que devino en uno de sus principales atractivos (Millán, 2014).

El proyecto Costanera en realidad trató de recuperar un área urbana relegada, ubicada en una zona estratégica cercana al centro que nunca antes había sido urbanizada ni reclamada. En otras palabras, las obras de la Costanera (que en parte se hicieron ganado terreno al río) conllevaron una ampliación del área central de la ciudad mediante la incorporación de nuevos terrenos urbanos (Brites, 2015). El paulatino avance de las obras, y de las relocalizaciones implicó la mudanza de miles de personas, definidas en aquel momento como "intrusos e ilegales”. Entre 1997 y 1998, solo el primer tramo de construcción de la Avda. Costanera (1750 metros), implicó la relocalización de 400 familias hacia tres complejos habitacionales, ya poblados por otros programas de relocalizaciones: A-4; Itaembé Miní, y A-3.2 (Villa Lanus) ${ }^{9}$ Estos conglomerados, además de estar alejados y desintegrados de la trama urbana, presentaban carencias de infraestructura, servicios y equipamientos socio-comunitarios.

La costanera se desarrolló de manera intermitente durante el periodo de 1998-2010 desarrollando una longitud de algo más de $5 \mathrm{~km}$ en el área más central de la ciudad. El desarrollo de esta franja costera posibilitó transformar la tradicional morfología urbana de la ciudad. El anegamiento y las obras hicieron desaparecer no solo numerosas barriadas, sino territorios importantes como la Laguna San José y la Península Heller (Figura 1), además de la desaparición de equipamientos históricos como el Puerto, Estación Ferroviaria y el Balneario El Brete. Por otro lado, de la mano de los procesos de relocalización, el caso de la avenida Costanera materializó una situación emblemática de segregación, generando un proceso de renovación urbana con matices particulares, en la medida en que quedó plasmado en el plano jurídico normativo de la legislación municipal, a partir del código de zonificación urbana; pero también su particularidad estuvo acentuada por el apoyo del sentido común colectivo: el consenso y el anhelo de la población local en pos de la ejecución de la obra.

La relocalización de numerosas barriadas ha sido un hecho emblemático de estas transformaciones y los programas de relocalización han minimizado u ocultado sus efectos negativos. En un contexto de pretraslado, casi la mayor parte de los pobladores realizaban trabajos informales (venta ambulante, changas, servicios domésticos, recicladores de residuos, etc.), pero la eficacia de sus estrategias de subsistencias se basaba en la cercanía al centro de Posadas o a sus áreas urbanas neurálgicas. Por otro lado, dentro de aquellos lugares de vida, con el tiempo se fueron configurando diversas estrategias de reproducción, reforzadas por la presencia de otros estratos sociales localizados en el entorno inmediato a los asentamientos (Brites, 2003). La particular ubicación de los asentamientos costeros implicaba para sus habitantes residir cerca de las áreas más densamente poblada de la ciudad: el centro y otros barrios de marcada identidad, (como los Aguacates, Villa Sarita, San Roque, etc.). Esto posibilitaba la generación de vínculos y relaciones entre compradores y vendedores de servicios, o de fuerza de trabajo, relaciones asimétricas que de hecho habían adquirido permanencia en el tiempo.

En este sentido, la proximidad espacial y social adquiría cierta importancia, puesto que las estrategias y expectativas de vida aquellos ha- 
bitantes costeros se inscribían en las condiciones de su participación en la trama de relaciones asimétricas de índole clientelar con los estratos socioeconómicos más pudientes de la zona; unas relaciones que, de hecho, garantizaban la obtención de ingresos y de satisfactores para los grupos domésticos. Así, en un contexto de pre-traslado, esta ubicación de los barrios de origen facilitaba no solo el desarrollo de trabajos informales, sino la eliminación de los gastos de transporte, así como la posibilidad de un acceso más amplio al mercado de trabajo urbano y el sostenimiento de redes sociales estructuradas de acuerdo al prolongado tiempo de residencia. La relocalización en un nuevo barrio muy distante de las zonas urbanizadas de la ciudad fracturó esas redes sociales y comunitarias, cruciales para la subsistencia.

Una vez finalizado los procesos relocalizatorios, la dificultad de movilidad territorial fue la primera restricción emergente en estos nuevos lugares de vidas. El trasladarse implicaba elevados costos en tiempo y dinero para una población pobre y con mayores niveles de carencias. Morar en las afueras de la ciudad generó "distancias" respecto al centro y a las zonas urbanizadas de la ciudad; en el centro está el comercio, el empleo, la administración, los servicios, etc. ${ }^{10}$ Por ello, hablar de los efectos de la relocalización implica referirse de manera paralela a las emergentes formas de vida en los conjuntos habitacionales. Por otro lado, al margen de las relocalizaciones, los programas de renovación "embellecieron" áreas claves de la ciudad, al tiempo que crearon nuevas áreas periféricas, destinadas a los sectores populares que (vía relocalización) debieron ceder espacios al avance de la ciudad formal.

\section{Segunda etapa: la revalorización}

Las obras complementarias de tratamiento costero tuvieron una continuidad espacial y temporal. Hacia el año 2010, la consolidación del nuevo frente costero fue posibilitando que la ciudad dispusiera de nuevos espacios para usos comerciales, recreativos, inmobiliarios y también residenciales. A continuación de los 5 kilómetros de Costanera en la parte más céntrica de Posadas, la EBY extendió las obras costeras con mayor intensidad a partir de la millonaria inversión que posibilitó el Plan de Terminación Yacyretá (PTY). ${ }^{11}$ En ese marco, se ejecutaron (en continuidad a las realizadas), dos mega-obras: la guarda costera de la Bahía El Brete ${ }^{12}$ y la construcción de la ruta Costera de acceso NorteSur que une la cabecera del puente Posadas-Encarnación con el municipio de Garupá. El conjunto de estas grandes obras se extendió algo más de 17 kilómetros sobre el nuevo frente fluvial, generando una situación que, sumada a las relocalizaciones masivas, dio origen al inicio de irreversibles procesos de transformación y revalorización urbana.

El Plan de Terminación Yacyretá tuvo una repercusión no solo a nivel territorial de Posadas sino a escala regional, desarrollando programas para reponer obras de infraestructura y recomponer la trama urbana, con hincapié en el desarrollo urbano, territorial y ambiental del nuevo frente fluvial. En Posadas, la recuperación paisajística y ambiental del borde costero se realizó por medio de un sistema de terraplenes y escolleras combinados con bloques de hormigón, permitiendo recuperar tierras y consolidar terrenos de cara al río. Concretamente, la ciudad adquirió una nueva línea de costa, con espacios verdes y parques de alta calidad, destinadas al ocio y el esparcimiento de la población. ${ }^{13}$ El conjunto de nuevos equipamientos urbanos, sumado al ele-
10 En ese contexto el trasporte se vuelve necesario, la gente tiene que ir y volver, desplazarse por la ciudad, lo que implica costos.

11 La firma del acuerdo en el año 2006 del Plan de Terminación de Yacyretá (PTY) entre Paraguay y Argentina ha posibilitado la ejecución de diversas acciones y obras de infraestructura con el objetivo de elevar el embalse hasta alcanzar la cota definitiva de 83 (m s.n.m.) en el eje de Encarnación-Posadas.

12 Para este sector, la EBY ha rediseñado un plan de tratamiento costero con el proyecto de "Bahía el Brete" el supuesto directo fue el aprovechamiento de las riberas del Paraná para el desarrollo turístico; pero de manera indirecta fue también la promoción de un mercado inmobiliario en el área de influencia.

13 Estos equipamientos urbanos habilitaron nuevos espacios públicos con áreas verdes, estacionamiento vehicular, ciclovía, pista para skate, canchas polideportivas, juegos infantiles, circuito peatonal, plazas saludables, pista de gimnasia, etc. 
mento paisajístico vinculado al río, promovió nuevas centralidades y procesos de renovación urbana. Esta acción, por otro lado, incidió en la transformación del espacio urbano, y en la incorporación de nuevas y valorizadas áreas al mercado inmobiliario.

Las obras que realizó la Entidad Binacional Yacyretá (costanera, saneamiento de arroyos, reconexión de tramas urbanas, etc.), redundaron en la transformación de la morfología del espacio urbano y fue expuesto como cambio positivo para la ciudad. De hecho, el eufemismo de la relación ciudad-río fue planteado en base a zonas urbanas costeras como paisaje construido (Fulco, 2011). La nueva línea de ribera protegida consolidó el crecimiento lineal sobre el eje costero del Paraná, irrumpiendo en la continuidad de la antigua costa y reconfigurando un área de inserción en forma de lagos interiores que configuran bahías y dársenas de diferentes escalas (Thomas, 2013). Esta situación fue capitalizada por la Municipalidad de Posadas, que propuso cambios en la legislación urbana a fin de acompañar los efectos socio-urbanos de Yacyretá, considerados positivos. Dentro de las políticas municipales, cabe resaltar el Plan Estratégico Posadas 2022 (PEP-2022) que propuso en 2010 intervenciones muy acentuadas en el área central y en el borde fluvial: río Paraná y arroyos urbanos (Figura 2).

Como complemento del PEP-2022, la municipalidad desarrolló hacia el año 2012 el Plan Urbano Ambiental Posadas (PUAP), el cual tuvo entre sus objetivos ordenar el borde ribereño: "Fomentar una cualificación espacial y formal del frente costero, alcanzando una adecuada vinculación entre la trama urbana y la costa, preservando los rasgos singulares del paisaje natural y construido, dotando a la ciudad de nuevas actividades y equipamientos que colaboren en la consolidación de su perfil turístico y el desarrollo socio-económico de la ciudad" (PUAP, 2012, p. 33).

Figura 2. Nuevas áreas de revalorización urbana. Fuente: Fondo de Desarrollo Urbano, PUAP, 2012.

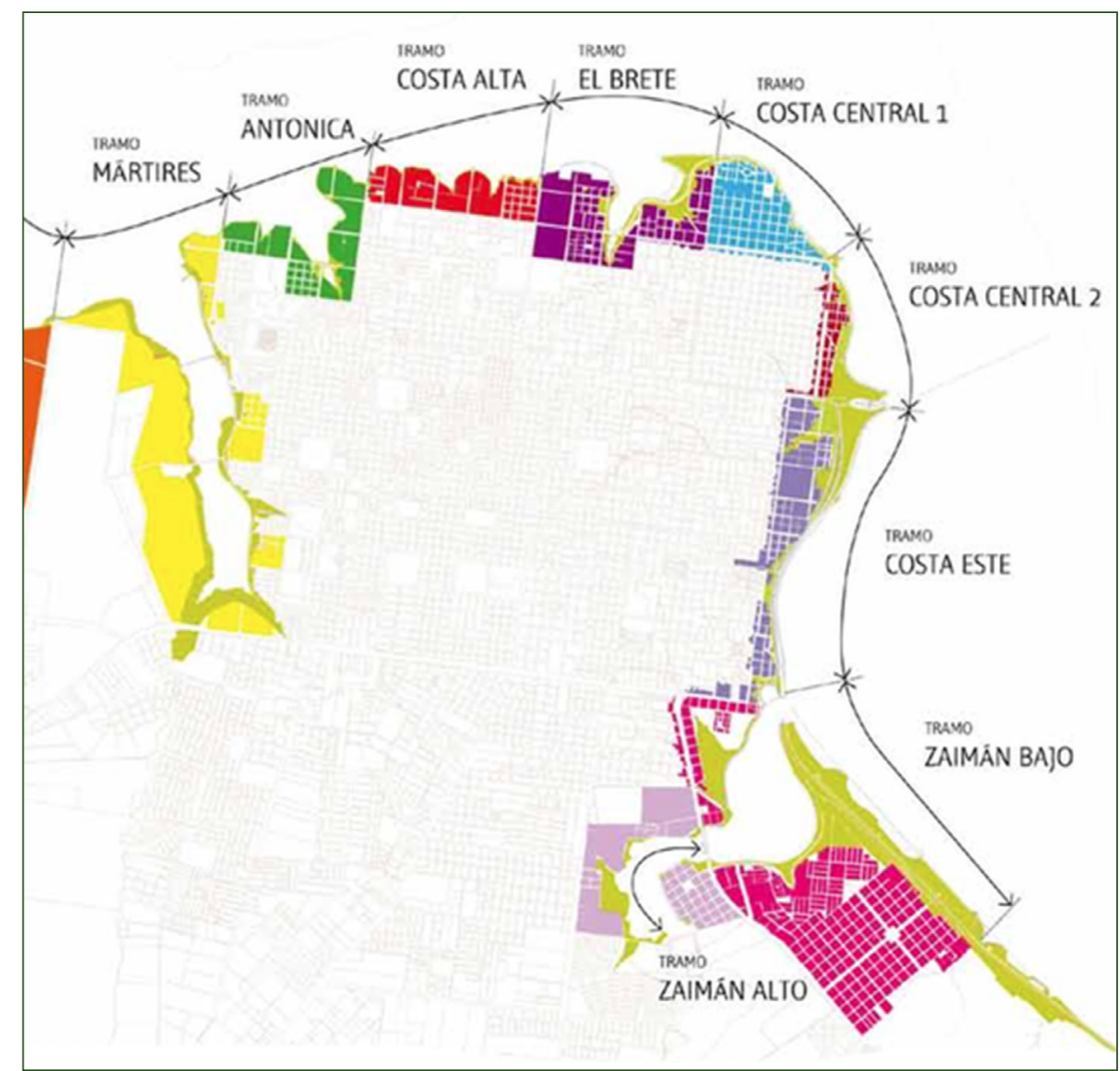




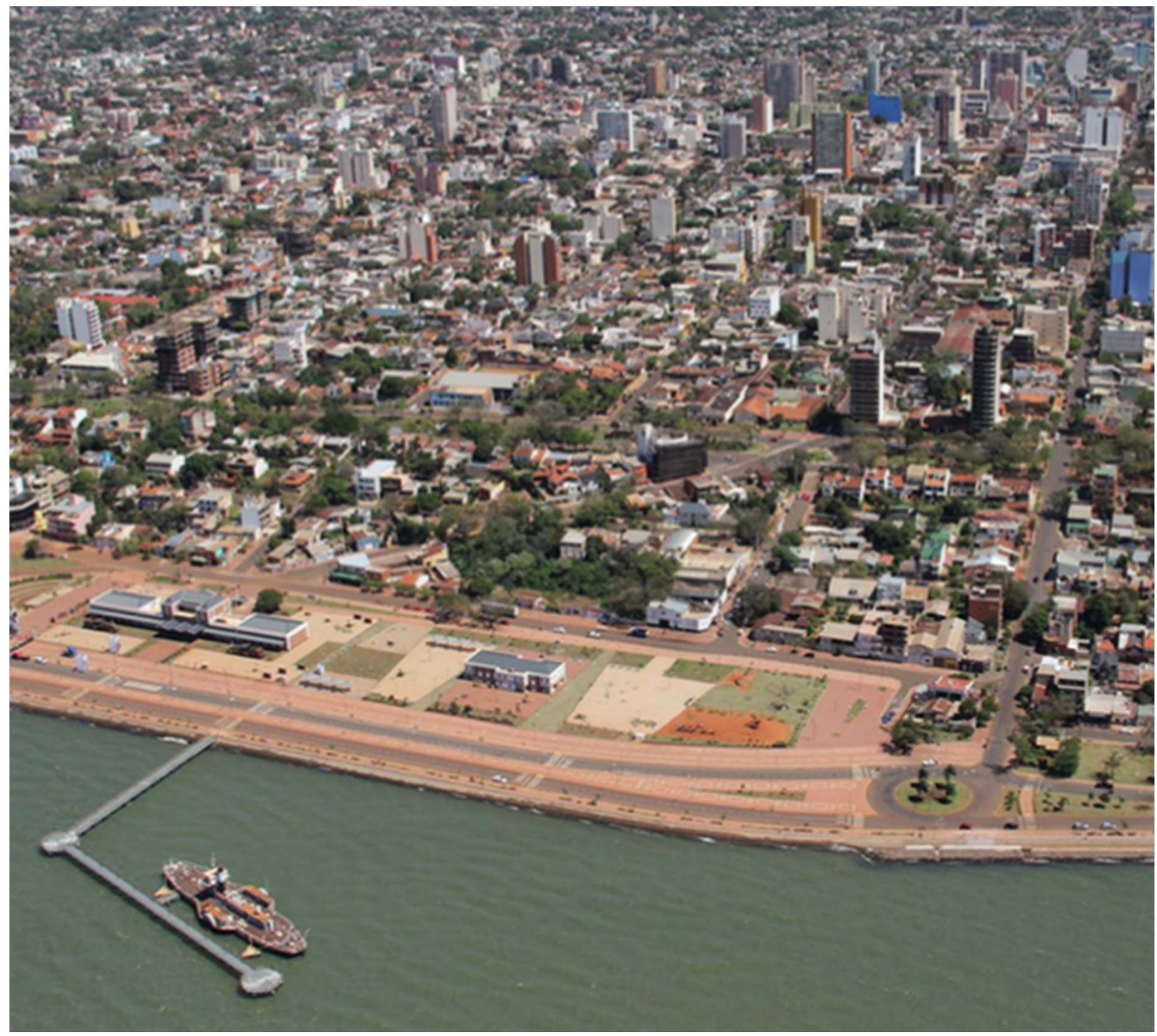

Este reordenamiento urbanístico, generado desde la escala supranacional (EBY) e impulsado desde el ámbito local (municipal), contribuyó a un nuevo orden urbano marcado por la revalorización del espacio. Ello implicó que la legislación y el planeamiento como efecto (deseado o no) pusieran en valor nuevas áreas que se fueron reurbanizando paralelamente al avance del nuevo frente fluvial. Así, el valor turístico/paisajístico incrementó de sobremanera los costos del suelo en zonas de fuerte revalorización urbana, impulsadas además por procesos especulativos del mercado inmobiliario, inclusive en terrenos adyacentes a la nueva línea de costa que bordea Posadas (Brites, 2016). En aquel marco, los diagnósticos del PUAP fueron esclarecedores: "Las obras de la represa de Yacyretá modificaron radicalmente el borde de la ciudad con el río Paraná: una nueva Avenida Costanera se encarga de articular a lo largo de su recorrido una serie de parques, plazas, paseos y balnearios que se convierten en una nueva "postal" de la ciudad y en el símbolo de la transformación urbana más significativa por la que ha atravesado la ciudad de Posadas" (PUAP, 2012, p. 32).
Figura 3. Foto de la renovada zona de la vieja estación de trenes. Fuente: PUAP, 2012. 
En este período de re-desarrollo urbano la ciudad asistió a una coyuntura caracterizada por la revalorización del espacio. Así, en paralelo a la finalización de las obras complementarias de Yacyretá, los tramos de la Costanera más próximos a la zona centro fueron siendo cada vez más apropiados por los sectores altos, al tiempo en que paulatinamente iba consolidándose como un espacio residencial de distinción, acompañado por una mixtura de usos destinados al ocio, tales como bares, restaurantes, pubs, etcétera.

Puede decirse que el auge de este proceso de renovación urbana dio lugar a nuevas formas de desplazamiento sin acción directa del Estado, es decir, producto de la dinámica del mercado inmobiliario. Este proceso puede ser interpretado como de gentrificación, en la medida en que su análisis revela dimensiones del cambio social en la ocupación del espacio. Claro está que, en este caso, se trata de un fenómeno más vinculado a los efectos de los grandes proyectos y del recurso paisajístico que presenta el nuevo frente fluvial.

Como antecedente de esta situación, puede señalarse el viejo barrio Villa Blosset, que data de más de 100 años. En un documento oficial, la transformación es descrita en estos términos:

Este es uno de los barrios más característicos de la ciudad. En Villa Blosset residían familias de bajos recursos económicos, como en un poblado a orillas del Paraná, hace pocos años fueron desalojados por el llenado del embalse Yacyretá. El resto del barrio es de clase socio-económica media, aunque están llegando cada vez más familias de clase media alta, debido, entre otros motivos, a que la Costanera Monseñor Kemerer bordea el mismo (SIG. Posadas, 2012, p. 28).

Precisamente esta área del cuarto tramo de la Costanera se regeneró a partir de la recuperación del patrimonio urbano ambiental con la Villa Cultural la Estación como infraestructura recreativa (Figura 3).

En parte, las obras de la costanera posibilitaron conectar el centro urbano de Posadas con el margen costero, generando una conexión más fluida y mejorando la cara fluvial de la ciudad. Esta transformación permitió procesos gentrificadores, no en el centro, sino en áreas pericentrales orientadas hacia el margen costero y hacia otras áreas donde las obras han regenerado y/o abierto ciertos espacios públicos.

Por otro lado, vinculado a los efectos Costanera, la EBY ha planteado como positiva la resignificación del patrimonio cultural. "El espacio costero ha posibilitado, revalorizar y resignificar lugares históricos de la ciudad como la denominada "Bajada Vieja"; así como, la ya mencionada resignificación de los edificios de la Estación Ferroviaria, y también - por efecto del plusvalor urbano que ella indujo- la recuperación y/o reciclaje de muchas edificaciones históricas de los barrios linderos" (PTY, 2011, p. 4). ${ }^{14}$

Como efecto de la remodelación urbana vinculada al río, otros barrios han desaparecido íntegramente: el Chaquito, Heller, parte de Baradero, etc. Más allá de la relocalización directa y compulsiva por parte del Estado, han permanecido en el área adyacente a la zona de costas y de recomposición urbanística barrios de sectores populares y asentamientos irregulares donde aún residen familias con deprimidas condiciones socio-económicas que, por su cercanía a las obras, han visto una revalorización de sus espacios residenciales antes caracterizados por el abandono y la desinversión.

14 Plan de Terminación Yacyretá (PTY) 2011. Proyecto 4: Unidad territorial urbana Costanera centro-Posadas. 
De acuerdo a estimaciones oficiales (EBY) en los últimos años, la tierra de la franja costera de Posadas ${ }^{15}$ aumentó entre 5 y 10 veces su valor, dependiendo de su ubicación en el distrito costero. Hacia el año 2015, el metro cuadrado sin mejoras (sin edificación) pasó de 50 a 250 y 300 U\$D, mientras que el metro cuadrado de construcción ascendió de 500 a $1200 \mathrm{U} \$ \mathrm{D}$. Otras estimaciones de agentes inmobiliarios que actúan en el mercado señalan que se dio un incremento de más del $300 \%$ en los valores de venta de las propiedades que se emplazan en la zona de costanera. Las inmobiliarias achacan el incremento a los trabajos de urbanización que ha realizado la EBY, observando que el fenómeno de cotización de valores dispares depende de la ubicación, la proximidad al centro, la vista al río, etc., y que la gran cantidad de demandas de viviendas en sentido vertical está incidiendo en la construcción de numerosos edificios en estas zonas. ${ }^{16}$ En el contexto de esta revalorización emergieron formalmente nuevos instrumentos de legislación urbana como el Fondo de Desarrollo Urbano (FDU 2012), con una marcada intensión orientada a la valorización de la propiedad inmobiliaria y a la recuperación de "plusvalías" en el ordenamiento urbanístico de Posadas

De forma resumida, puede afirmarse que el Proyecto Yacyretá ha generado una impronta en la re-urbanización de Posadas y los procesos de renovación concomitantes se han estado desarrollando de varias maneras: 1) a través de la acción concreta y puntual de los programas públicos de relocalización de la población afectada por las obras de intervención urbana; 2) el cambio del entorno adyacente generado tanto por las obras de infraestructuras como por las actividades inmobiliarias a través de la compra y la destrucción de las viviendas originales. Esta dinámica culmina con la posterior construcción de edificios nuevos para sectores de mayor poder adquisitivo. Esta acción se desarrolla con variada intensidad y demuestra que las obras en el nuevo frente fluvial no solo han generado grandes operaciones urbanísticas públicas, sino también la especulación inmobiliaria y el desarrollo de emprendimientos privados con incremento de plusvalías.

\section{Tercera etapa: los asentamientos que hoy persisten}

Finalizado el proceso relocalizatorio y las obras de tratamiento costero, han permanecido distintos asentamientos informales localizados en diferentes áreas de influencia del nuevo frente costero que bordea Posadas. Éstos habían quedado cuasi-invisibilizados en áreas urbanas intersticiales transformadas, mientras que otros fueron parcialmente demolidos, pero subsistieron por hallarse fuera de la zona de afectación. Parte de las Charcas 213 y 210 (Villa Urquiza), las Chacras 178, 181, Parque Adam, Viejo Rowing, Villa Flor y Cerro Pelón, son solo algunos de estos asentamientos que persistieron en zonas que hoy están asistiendo a fuertes procesos de renovación urbana (Tabla 2).

\begin{tabular}{|l|c|l|}
\hline Asentamientos & Flia. & Tipo de espacio \\
\hline $\begin{array}{l}\text { Ch. } 186 \text { (Aguado/Alma Fuerte } \\
\text { y Río Paraná) }\end{array}$ & 39 & $\begin{array}{l}\text { Vía Pública/entorno residen- } \\
\text { cial }\end{array}$ \\
\hline Villa Flor. (Ch. 27). & 79 & Privado/entorno residencial \\
\hline $\begin{array}{l}\text { Ch. 17 (Villa Urquiza Costa- } \\
\text { nera) }\end{array}$ & 60 & $\begin{array}{l}\text { Suelo estatal/entorno residen- } \\
\text { cial }\end{array}$ \\
\hline
\end{tabular}

15 Como al igual de las ciudades de Garupá y Candelaria que forman el área metropolitana afectada por el embalse. 16 Para el año 2015, de acuerdo a los valores de mercado el $\mathrm{m}^{2}$ de terreno oscila entre $\$ 8000$ a $\$ 10000$ (pesos argentinos). En tanto el $\mathrm{m}^{2}$ de departamentos va de $\$ 20000$ a $\$ 25000$ pesos. Estimaciones de inmobiliarias asociadas a la Cámara de Inmobiliaria de Misiones (CIM) y la Red de Inmobiliaria de Misiones, (REDIM). 
Tabla 2. Asentamientos en áreas revalorizadas. Fuente: elaboración propia en base a Municipalidad de Posadas, 2015.

\begin{tabular}{|l|c|l|}
\hline Asentamientos & Flia. & Tipo de espacio \\
\hline $\begin{array}{l}\text { Ch. } 213 \text { y } 11 \text { (Villa Urquiza } \\
\text { Costanera) }\end{array}$ & 20 & Privado/entorno residencial \\
\hline Ch. 43 (Av. Urquiza, Lavalle) & 28 & Privado/entorno residencial \\
\hline $\begin{array}{l}\text { Ch. } 65 \text { (T. Guido y Centena- } \\
\text { rio) }\end{array}$ & 40 & Privado/entorno residencial \\
\hline $\begin{array}{l}\text { Ch. } 181 \text { (Urquiza y San Mar- } \\
\text { tín) }\end{array}$ & 450 & $\begin{array}{l}\text { Suelo estatal (Ejército)/entor- } \\
\text { no residencial }\end{array}$ \\
\hline Ch. 189 (Av. Alem y Calle 119) & 64 & $\begin{array}{l}\text { Privado/Público. Entono resi- } \\
\text { dencial }\end{array}$ \\
\hline Ch. 188 (Zapiola y río Paraná) & 20 & $\begin{array}{l}\text { Vía Pública/entorno residen- } \\
\text { cial }\end{array}$ \\
\hline $\begin{array}{l}\text { Ch. } 210 \text { (Costanera y F. Agui- } \\
\text { rre) }\end{array}$ & 25 & Privado/entorno residencial \\
\hline Ch. 178 (Av. Uquiza y C. Miño) & 120 & $\begin{array}{l}\text { Suelo estatal/entorno residen- } \\
\text { cial }\end{array}$ \\
\hline Cerro Pelón & 60 & Privado/entorno residencial \\
\hline Viejo Rowing Ch. 222 y 26 & 85 & Privado/entorno residencial \\
\hline
\end{tabular}

En la zona de la actual Bahía El Brete han desaparecido barriadas enteras como, el Tiro Federal, El Brete, $\mathrm{B}^{\circ}$ YPF, Pira Pitá, $\mathrm{B}^{\circ}$ de Laosianos (Figura 4). En tanto unos pocos asentamientos quedaron y hoy gozan de buena localización en la trama urbana, además de ocupar lugares que ofrecen a sus residentes una estructura de oportunidades para la vida cotidiana, en términos de su accesibilidad al espacio urbano. En muchos casos, las ventajas asociadas a la localización de la vivienda no solo son funcionales o atractivas por la presencia del nuevo margen de costa, sino convenientes por su proximidad al mercado de trabajo urbano y el acceso a servicios, minimizando tiempos, distancias, costos en transporte etc. No obstante, son asentamientos que han comenzado paulatinamente a ser cercados, acorralados por obras públicas y nuevas y crecientes edificaciones privadas que están transformando el entorno y despertando variados intereses de sectores sociales de mayor poder adquisitivo.

A modo de ejemplo, puede citarse la Chacra 181, que hoy con más de 450 familias, es un asentamiento que manifiesta las ventajas de su localización: su proximidad al río y al balneario, así como a las oportunidades laborales, junto con sus cortas distancias y su conectividad con otras áreas y sectores de la ciudad, etc., constituyen circunstancias muy valoradas entre sus residentes. La Chacra 181, asentada desde 1983 sobre tierras públicas (del Ejército Argentino), ha quedado actualmente ubicada en un área de fuerte revalorización urbana, próxima al club náutico Pira Pytá y a barrios residenciales para sectores altos. Un área de opulencia, donde se han construido grandes y suntuosas viviendas, además del primer Country de la ciudad. Casi en la misma situación se encuentra el asentamiento de la Chacra 178, ubicado en el área de influencia de la bahía El Brete y de la nueva Reserva Urbana del arroyo Itá, donde la especulación inmobiliaria elevó abruptamente los costos del suelo en los alrededores (Figura 5). 


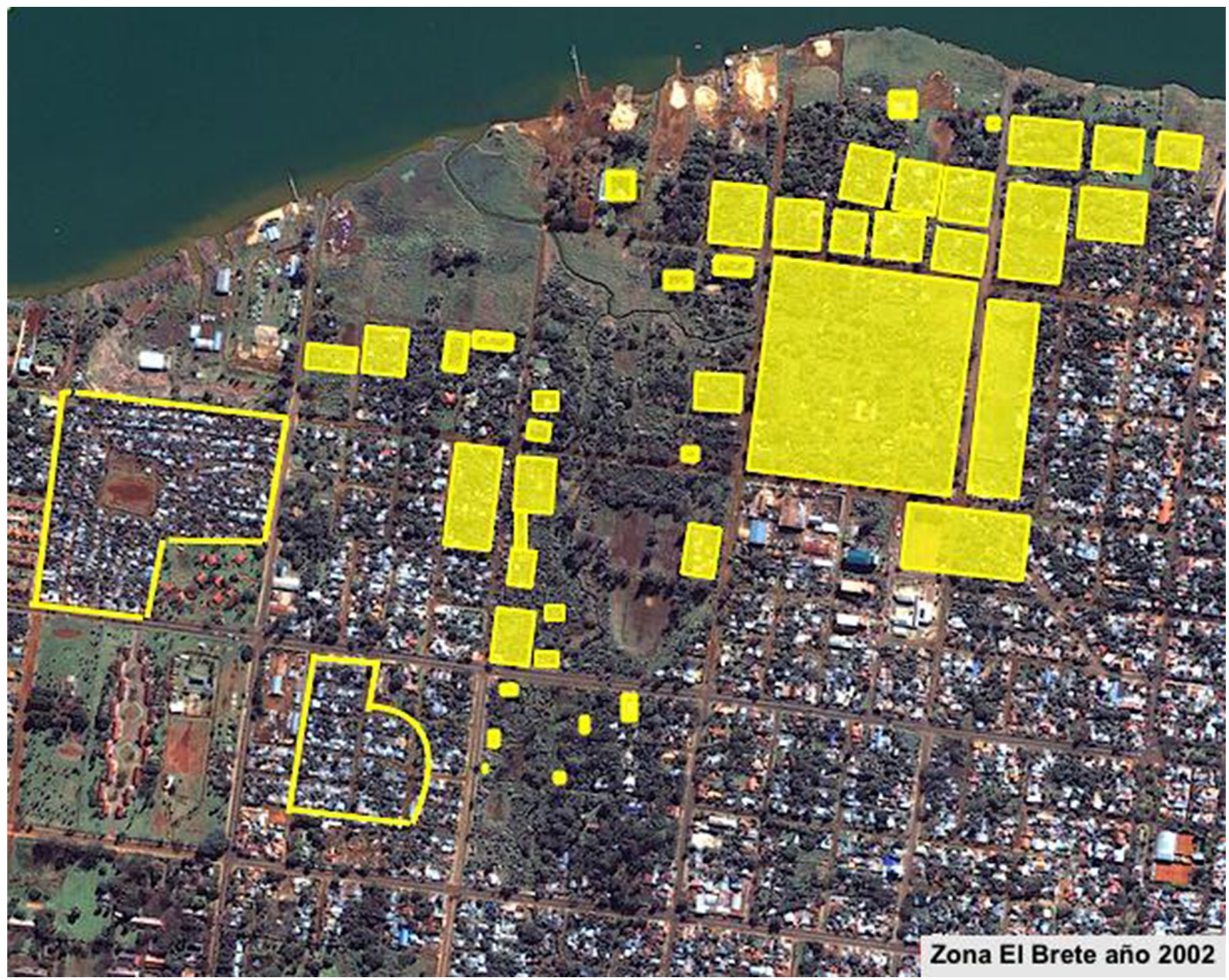

Los cambios en el entorno han expuesto a estos asentamientos a nuevas visibilidades urbanas, emergidas desde propuestas de planes oficiales de intervención y hasta la aparición de propietarios privados ausentistas (supuestos dueños) que reclaman la posesión de las tierras, como en los casos del Cerro Pelón y Viejo Rowing, donde han existido amenazas y litigios aún sin dirimir. De hecho, muchos asentamientos localizados en diferentes áreas de influencia del nuevo frente fluvial son calificados como intrusos e ilegales: "viviendas precarias con carencias de servicios e infraestructuras se disponen sobre tierras tanto de dominio público (municipal) como privados, interrumpiendo en algunos casos la vía pública y los trazados de calles" (PUAP, 2012, p. 36). ${ }^{17}$ Este discurso peyorativo de-construye el hábitat de los pobres y conlleva potenciales acciones de desalojo de aquellos hogares que aún persisten en áreas clave de revalorización urbana. El conjunto de estas prácticas de amedrentamiento legal y jurídico están volviendo más incierta la vida futura en estos asentamientos.

El hábitat de estos asentamientos atraviesa por una contradicción: por un lado, se encuentran en entornos urbanos altamente revalorizados y embellecidos y, por otro, se localizan en intersticios, en cuyo interior la provisión de infraestructura y servicios es todavía precaria y escasa. Actualmente, la situación de los asentamientos informales es compleja, pues transcurridos los grandes cambios urbanísticos, han
Figura 4. Zona El Brete antes de la intervención. Fuente: elaboración propia en base a ortoimagen tomada de Google Earth.
17 De hecho, el Puap, 2012, plantea la renovación urbana en el sitio del Cerro Pelón y su entorno inmediato. 


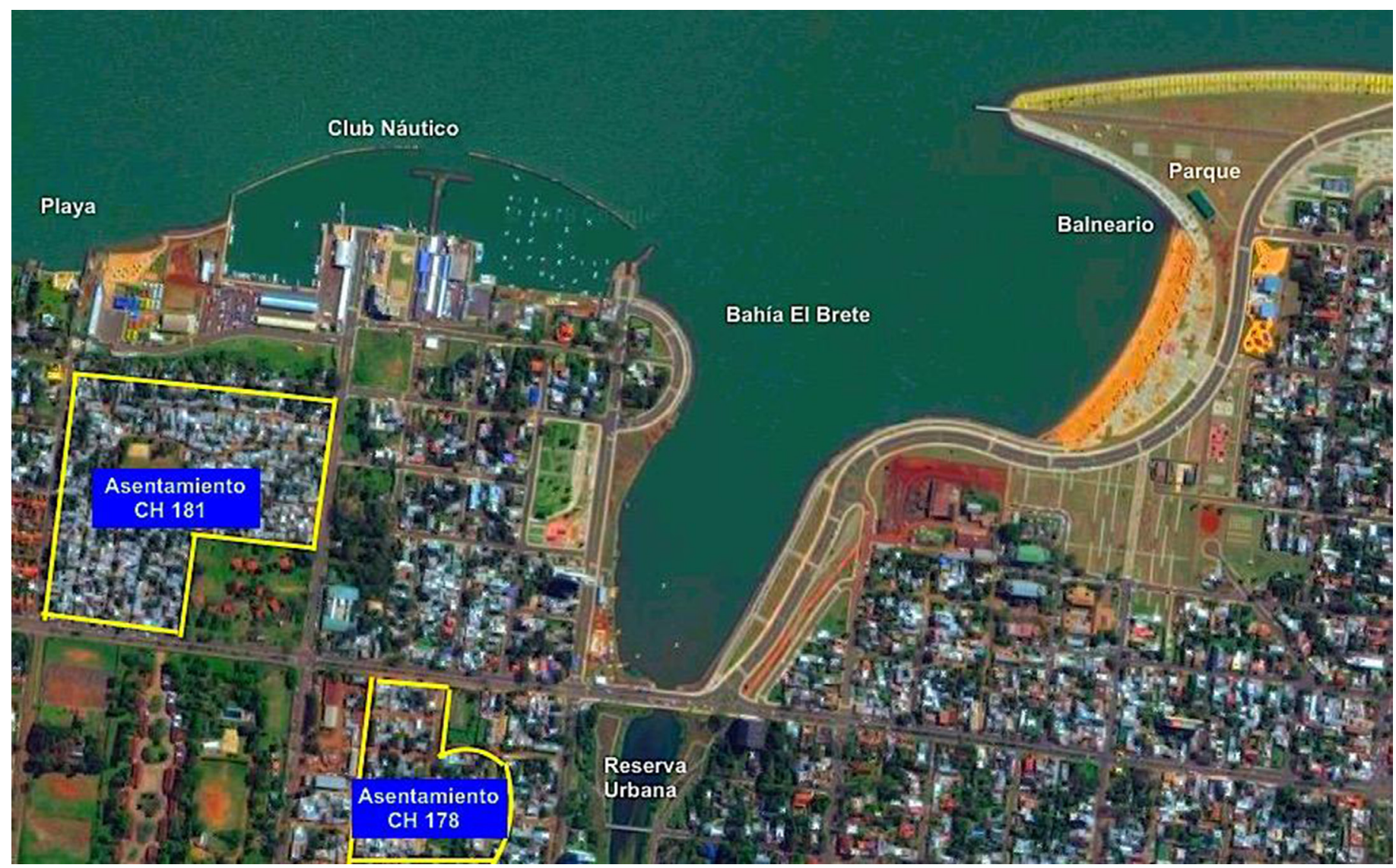

Figura 5. Nueva área costera de la Bahía El Brete y los asentamientos que persisten. Fuente: elaboración propia en base Google Map. emergidos otros asentamientos en distintos puntos de la trama urbana y se han sumado a aquellos que permanecieron en los intersticios de la renovación urbana. Es notorio que los lugares que ocupan estos asentamientos son residuales, intersticiales, pero estratégicos en el contexto urbano. Son residuales frente al avance de las obras de infraestructura que fue dejando la ciudad formal, y estratégicos de cara a las estructuras de oportunidades que otorga su ubicación: proximidad al trabajo, a los nuevos espacios de esparcimiento, minimización de tiempos, distancias y costos de transportes.

El estudio de los asentamientos no puede quedar desvinculado de su ubicación en el espacio urbano, así como de un análisis que revise el modelo de desarrollo a gran escala. Finalizadas las obras en el nuevo frente fluvial, persisten más de 12 asentamientos en áreas de revalorización y de mayor acceso al espacio urbano, a diferencia de aquellos que se localizan en zonas periféricas, aisladas y más segregadas socio-espacialmente, donde hay mayores adversidades para la vida urbana (falta de infraestructura, servicios y oportunidades).

Como marco más general, los cambios que se objetivan hoy en la ciudad de Posadas tienen vinculación con las consecuencias derivadas del proyecto hidroeléctrico Yacyretá, aún a pesar de haber transcurrido más de 30 años de la primera experiencia relocalizatoria. La revalorización del borde costero, el desarrollo de nuevos modos de vida y de ocio vinculado al río, las disputas por los diversos espacios, su ocupación y explotación, etc., constituyen nuevas experiencias urbanas, que, aunque se desenvuelven en una coyuntura espacio-temporal, siguen fuertemente condicionado por el proyecto Yacyretá, que desarrolló obras en gran escala. En otras palabras, el proceso de producción del espacio urbano a través de los programas de Yacyretá contribuyó a articular herramientas urbanísticas de generación público-privada de 
plusvalías urbanas muy acorde al modelo de acumulación capitalista (Millán, 2014). Un contexto en el que la legislación y las nuevas normativas urbanísticas parecen favorecer los intereses privados y especulativos de los sectores altos con respecto a la construcción de viviendas y otros emprendimientos en espacios aledaños a la costa. De hecho, de manera explícita, el Estado propicia la renovación urbana a partir de la inversión privada, con viviendas individuales y colectivas en terrenos próximos a zonas de paseo costero.

La implementación de proyectos urbanísticos trajo aparejados procesos de revalorización urbana con efectos sobre el mercado del suelo y la emergencia de nuevas formas de desplazamientos cada vez más clasistas que impiden el derecho al espacio urbano y el hábitat de los sectores populares, fracturando las relaciones entre los sectores sociales. De modo que estas intervenciones derivan en procesos de recualificación urbana y, por lo tanto, en la lucha entre los diferentes sectores sociales por su ocupación y/o permanencia en esos espacios revalorizados. De este modo, detrás de la idea de una ciudad que se embellecería mirando el río, Posadas asiste a un rediseño urbano que está contribuyendo al enfrentamiento entre la ciudad formal y la ciudad informal.

\section{Reflexiones finales}

La concreción del proyecto Yacyretá dio impulso al re-desarrollo de la ciudad formal, materializando nuevos reordenamientos socio-espaciales, a través de programas de relocalización y de políticas de intervención/renovación urbana, que no solo eliminaron muchos asentamientos informales, sino que generaron nuevas áreas de expansión de la centralidad. Así, en nombre del desarrollo urbano, se erradicó la ciudad informal de la larga zona de costa, para construir en ese espacio la ciudad formal, abierta al río.

El desplazamiento de miles de familias asentadas en urbanizaciones informales y barrios populares, a pesar de ser destacado como un hecho emblemático de desarrollo, constituyó un episodio dramático que generó un efecto segregador. El desplazamiento desde una zona más integrada al centro urbano (y al mercado de trabajo) hacia otra más lejana y aislada de las áreas centrales incidió no solo en la pérdida del derecho al espacio urbano y a las estructuras de oportunidades vinculadas al hábitat, sino también en las prácticas reproductivas. Un proceso en paralelo a programas de relocalización que buscaron minimizar u ocultar sus efectos adversos.

El análisis en el tiempo deja entrever cómo, a lo largo de su ejecución, el proyecto hidroeléctrico Yacyretá debió proveer de defensas costeras en los bordes del río Paraná y arroyos urbanos, rehabilitando amplios sectores urbanos y recomponiendo urbanísticamente Posadas. Un proceso que, con los años, está posibilitando analizar los efectos de segunda generación del proyecto: entre los que se cuentan la emergencia de la especulación inmobiliaria y de la inversión privada, de la revalorización, y la gentrificación como nuevas formas de desplazamientos al margen de la acción directa del Estado.

A pesar de la finalización del proyecto Yacyretá, la regeneración del nuevo margen de costa está poniendo al descubierto viejos asentamientos informales en espacios muchas veces adyacentes a la nueva línea de costa, donde la revalorización/reurbanización es creciente. El efecto Yacyretá, ha dado vía libre a las presiones del mercado inmobiliario, el 
avance de la ciudad legal y, por ende, a la demanda de los sectores de mayor poder adquisitivo. El conjunto de estos procesos y transformaciones está contribuyendo a la emergencia de un espacio urbano y residencial más segregado. Hoy se están produciendo numerosos procesos especulativos asociados al desplazamiento de estos asentamientos informales a raíz de la incorporación a la estructura urbana de nuevas áreas recualificadas, lo que ha despertado una marcada incertidumbre por la tenencia de la tierra en un contexto de creciente proceso de valorización del espacio urbano que habitan. 


\section{Referencias bibliográficas}

Bartolomé, Leopoldo J. (2006) Reasentamientos forzados y el sistema de supervivencia de los pobres urbanos. AVA-Revista de Antropología, 8. 56-75. Recuperado el 30 de mayo de 2020 de: https:/ / www. redalyc.org/articulo.oa?id=169021397003.

Borio, Carlos (2002). ¿Quo vadis Posadas? Reseña sobre la evolución urbanística de Posadas. Gaia Misiones. Recuperado el 20 de abril de 2020 de: https:// sites.google.com/site/gaiamisiones/articulos/quovadis-posadas.

Brites, Walter Fernando (2003). Relocalizados: exclusión territorial y vulnerabilidad incrementada. En Revista Antropología y Derecho CEDEAD, 2(1), 18-22.

Brites, Walter Fernando (2015). Repensando el efecto de las relocalizaciones: acerca de la segregación socio-espacial en Posadas. Revista sobre Estudios e Investigaciones del Saber Académico, 9, 87-92. Recuperado el 4 de mayo de 2020 de: http:/ / publicaciones.uni. edu.py/index.php/eisa/article/view/98/78.

Brites, Walter Fernando (2016). Grandes proyectos y sus efectos sociales. Tendencias a la sustitución social en espacios urbanos revalorizados. ACE: Architecture, City and Environment, 11(32), 13-32. DOI: 10.5821/ace.11.32.3964.

Brites, Walter Fernando (2017). La ciudad en la encrucijada neoliberal. Urbanismo mercado-céntrico y desigualdad socio-espacial en América Latina, en Urbe. Revista Brasileira de Gestão Urbana, 9(3), 573586. DOI: 10.1590/2175-3369.009.003.ao14.

Catullo, María (2006). Ciudades Relocalizadas. Una mirada desde la Antropología Social. Buenos Aires: Editorial Biblos.

Dirección General de Catastro (1988). Informe: caracterización de Posadas por radio censales. Provincia de $\mathrm{Mi}-$ siones. Dirección General de Estadísticas y Censos. Dpto. Capital. Municipalidad de Posadas.

FDU - Fondo de Desarrollo Urbano (2013). Plan Urbano Ambiental Posadas. Unidad Ejecutora de Proyectos Especiales (UEPE), Municipalidad de Posadas.

Fulco, Alberto (2011). El paisaje costero como factor de integración. El proyecto hidroeléctrico Yacyretá y las transformaciones del paisaje en las Zonas urbano-costeras de las ciudades involucradas en el periodo 2005-2010 (Tesis de Maestría). Facultad de Arquitectura y Urbanismo, Universidad Nacional de La Plata.

García Hernández, Norma (2005). Los asentamientos informales en las ciudades latinoamericanas. De espacios segregados a factores de crecimiento urbano. Ponencia en Pensamiento y propuestas: 20 años del $S A L$, XI Seminario de Arquitectura Latinoamericana (SAL). Universidad Autónoma Metropolitana (Azcapotzalco y Xochimilco), México.
Gasic Klett, Ivo (2013). Gentrificación en el pericentro metropolitano del Gran Santiago. El rol de los gobiernos locales en la actividad inmobiliaria de renovación urbana y su efecto en el desplazamiento exclusionario de residentes en seis comunas pericentrales (2000-2012) (Tesis de Pregrado para la carrera de Geografía). Facultad de Arquitectura y Urbanismo, Universidad de Chile, Santiago de Chile.

Jaramillo, Samuel (2003). Los fundamentos económicos de la "participación en plusvalías". Documento preparado para el Centro de Investigación y Docencia Económicas, CIDE, Universidad de Los Andes y el Lincoln Institute of Land Policy (Inédito). Recuperado el 29 de enero de 2020 de: http:/ / www.institutodeestudiosurbanos.info/dmdocuments /cendocieu/Especializacion_Mercados/Documentos_ Cursos/Fundamentos_Economicos_ParticipacionJaramillo_Samuel-2003.pdf.

Lins Ribeiro, Gustavo (1985). Proyectos de gran escala: hacia un marco conceptual para el análisis de una forma de producción temporaria. En Bartolomé Leopolgo. (ed.), Relocalizados: Antropología social de las poblaciones desplazadas (pp. 49-66). Buenos Aires: IDES.

Lungo, Mario (2011). Grandes proyectos urbanos: una visión general. En Lungo, Mario (ed.), América Latina: países pequeños de grandes ciudades (pp. 93-138). Quito: Olacchi (Colección Textos urbanos, Volumen X).

Millán, María (2014). El balcón al Paraná: narrativa de la transformación del borde costero. En Millán, María y Brites, Walter (eds.) Ciudades Vivas. Imaginaciones sobre el territorio (pp. 335-387). Posadas: Creativa.

Municipalidad de Posadas (2015). Diagnóstico del estado de situación de asentamientos en el municipio de Posadas 2014-2015. Coordinación del programa de regularización de espacios públicos y provisión de agua.

PEP-2022 (2010). Plan Estratégico Posadas 2022 (PEP 2022). Municipalidad de Posadas.

POBUR (1996). Determinantes estructurales y estrategias reproductivas de la pobreza urbana. Tercer informe final. CONICET-UNaM.

PTY (2011). Plan Terminación Yacyretá. Resumen Ejecutivo del PTY al mes de diciembre de 2011. Entidad Binacional Yacyretá. Posadas (Inédito).

PUAP (2012). Plan Urbano Ambiental Posadas (PUAP). Municipalidad de Posadas.

Radovich, Juan Carlos (2017). Impacto social del proyecto hidroeléctrico Chihuido I, Neuquén, Argentina. En Brites, Walter; y Catullo, María (eds.). Ciudades, desarrollo y consecuencias sociales de grandes proyectos. Experiencias regionales en análisis (pp. 18- 
45). Encarnación: Centro de Investigación y Documentación, Universidad Autónoma de Encarnación (CIDUNAE). Recuperado el 27 de enero de 2020 de: http://works.bepress.com/walterf-brites/21.

Roitman, Sonia (2004). Urbanizaciones cerradas: estado de la cuestión hoy y propuesta teórica. Revista de Geografía Norte Grande, 32, 5-19.

Sabatini, Francisco; Gonzalo Cáceres; y Jorge Cerdá (2001). La segregación residencial en las principales ciudades chilenas. Revista EURE, 27(82), 21-42.

Serje, Margarita (2011). Los dilemas del reasentamiento: Introducción a los debates sobre procesos y proyectos de reasentamientos. En Serje, Margarita; y Anzellini, Stefano (eds.) Los dilemas del reasentamiento (pp. 17-42). Bogotá: Ediciones de la Universidad de los Andes.
SIG- Sistema de Información Geográfica (2012). Informe Barrios, Noviembre, p. 34. Municipalidad de Posadas (Inédito).

Thomas, Oscar Alfredo (2013). Yacyretá: energía para el desarrollo 1973-2013. Buenos Aires: Contratiempo Ediciones.

Ugalde Monzalvo, Marisol (2012). Renovación urbana sostenible. Ponencia en Think Green 2012: Economía verde y desarrollo sostenible en México. Instituto Global para la Sostenibilidad, Ciudad de México, México.

Varela, Omar David; y Cravino, María Cristina (2008). Mil nombres para mil barrios. Los asentamientos y villas como categorías de análisis y de intervención. En Cravino, Cristina (ed.), Los mil barrios in-formales (pp 45-64). Buenos Aires: Universidad Nacional de General Sarmiento.

Brites, Walter Fernando (2020). Yacyretá y los efectos de segunda generación. Desarrollo urbano, asentamientos y avance de la ciudad formal. Hábitat y Sociedad, 13, 229-248.

<http://dx.doi.org/10.12795/HabitatySociedad.2020.i13.13> 